\title{
Stochastic debt sustainability analysis for sovereigns and the scope for optimization modeling
}

\author{
Andrea Consiglio ${ }^{1} \cdot$ Stavros A. Zenios ${ }^{2,3,4}$
}

Received: 4 April 2017/Revised: 30 April 2017/Accepted: 1 May 2017

(C) Springer Science+Business Media New York 2017

\begin{abstract}
We argue that sovereign debt sustainability analysis must be augmented by stochastic correlated risk factors and a risk measure to capture tail effects. Crisis situations can thus be adequately specified and analyzed with sufficient accuracy to warrant the relevance of policy decisions. In this context there is significant scope for optimization modeling for both strategic planning and operational management. We discuss diverse aspects of the problem of debt sustainability and highlight modeling approaches that can be brought to bear on the problem. Results with the fictitious, but nor unrealistic, Kingdom of Atlantis, which is sinking under excessive debt, illustrate the proposed models.
\end{abstract}

Keywords Sovereign debt · Debt restructuring - Restructuring · Sustainability · Scenarios $\cdot$ Portfolio optimization $\cdot \mathrm{CVaR}$

\section{The persistence of debt crises and model failures}

The Eurozone sovereign debt crisis, with the restructuring of Greek sovereign debt held by private investors, renewed awareness of the persistence of sovereign debt crises. Of course, Argentina had been making headline news since early 2005 when President Nestor Kirchner declared "We will not pay our debt with the hunger and

Stavros A. Zenios

zenios.stavros@ucy.ac.cy

Andrea Consiglio

andrea.consiglio@unipa.it

1 University of Palermo, Palermo, Italy

2 University of Cyprus, Nicosia, Cyprus

3 Norwegian School of Economics, Bergen, Norway

4 Wharton Financial Institutions Center, University of Pennsylvania, Philadelphia, PA, USA 
thirst of the Argentine people". International authorities, including rock star Bono, supported his decision (Maurer and Musacchio 2006). With the Eurozone crisis the problem stopped being just for emerging markets and became also a problem for advanced economies. Eurozone brought sovereign debt crises to the mainstream, and the work of Minsky (1986) on the inherent instability of the financial system was revived. Sovereign debt crises are persistent, and the challenge of "serial defaulters" reached the General Assembly of the United Nations. In Sept. 2014 a resolution was adopted to "negotiate and adopt a multilateral legal framework for sovereign debt restructuring”, and in Sept. 2015 Resolution 69/319 was adopted on "Basic Principles on Sovereign Debt Restructuring Processes" (Li 2016; Guzman and Stiglitz 2016).

There is a dearth of normative models for dealing with this important problem. In a Harvard Business Law Review article, Wright (2012) argued for "Criteria for an 'Optimal' Debt Restructuring Process". The author approached the problem from a legal and institutional perspective - there is no modeling in the paper-and it is for a very good reason that 'optimal' is placed within quotes: for such a complex problem it is impossible to postulate a well-defined optimality criterion. In this paper we argue that existing tools of Debt Sustainability Analysis need to be augmented with stochastic correlated risk factors-Stochastic Debt Sustainability Analysis - and a risk measure introduced to capture tail effects. Optimization models emerge then as powerful tools to answer three interrelated questions at the core of debt sustainability analysis:

Q1 Is debt sustainable with high probability, say 95\%?

Q2 If debt is unsustainable, what debt restructuring schedule will restore sustainability?

Q3 What is the optimal debt financing strategy for the sovereign, with or without restructuring?

Q1 and Q3 together determine if debt can be financed in a sustainable way.

Optimization models for planning under uncertainty are well suited for both strategic and operational planning for sovereign debt problems. We sketch some models to challenge interested readers and create awareness of a broad problem class. This is not a survey paper. We cite a few seminal contributions and some of our own work. A broadbrush sketch of sovereign debt issues covers several topics. There is the question of how much debt a sovereign can service without undue burden on economic growth (Bohn 1995) and avoiding "debt overhang" (Krugman 1988). There is the question of how to finance debt with smooth taxes (Barro 1979), and the trade-off between costeffective debt financing, given the term structure of interest rates, and the rollover risk created when there is concentration of debt issues (Alesina et al. 1990; Calvo 1988). There are legal and policy issues relating to debt restructuring (Buchheit et al. 2013). The economics literature is vast, and interested readers are referred to Dornbusch and Draghi (1990) and Reinhart et al. (2015) for the basics of sovereign debt management and debt crises in general. Neck and Sturm (2008) and Sturzenegger and Zettelmeyer (2006)) are recent works on sovereign debt crises. Consiglio and Zenios (2016) describe the salient features of the problem leading to a fully-specified model.

The societal impact of 'optimal' sovereign debt management can be significant. From a Bank of Canada database we learn that up to half of the world's sovereigns 


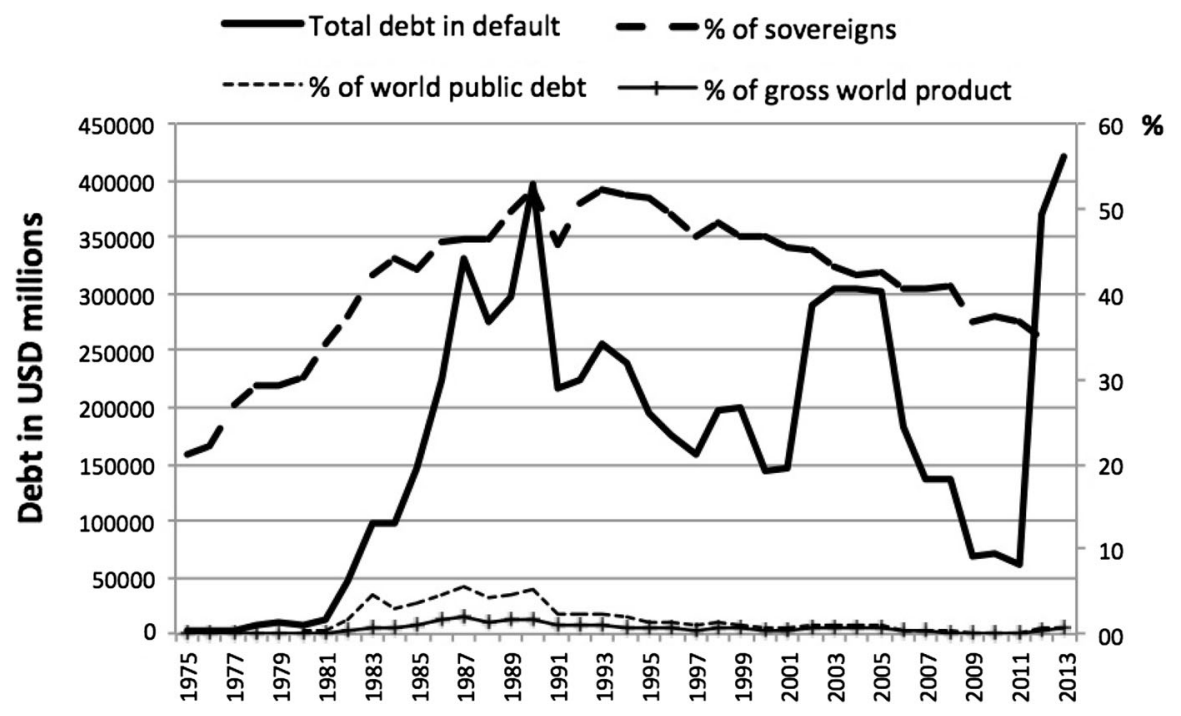

Fig. 1 The prevalence and magnitude of sovereign debt defaults worldwide Data Beers and Nadeau (2015)

were afflicted by debt crises with debts in the 100's of billions USD; Fig. 1. But it is not only the magnitude and complexity of the problem that deserves the attention of optimization modelers. Failures of existing (static) debt sustainability analysis are well documented in the literature. They are mostly manifested by over-optimistic projections that lead to inadequate policies and a prolongation and deepening of the crisis. A recent critique was articulated by Guzman and Heymann (2015), who report past IMF projections for a number of countries and compare with realized performance. Their key findings are shown in Table 1. IMF has been aware of the problem and Celasun et al. (2006) argue for a "fan charts" approach to debt sustainability. This is an important step in the right direction, and if it becomes widely adopted it will pave the way for the models we describe. However, it is not

Table 1 Debt-to-GDP ratio projections (\%) by IMF and the realized values Source: Guzman and Heymann (2015)

\begin{tabular}{lllccc}
\hline Country & $\begin{array}{l}\text { Year of IMF } \\
\text { review }\end{array}$ & $\begin{array}{l}\text { Year of } \\
\text { projection }\end{array}$ & $\begin{array}{l}\text { Baseline } \\
\text { projection }\end{array}$ & $\begin{array}{l}\text { Extreme } \\
\text { projection }\end{array}$ & $\begin{array}{l}\text { Realized } \\
\text { values }\end{array}$ \\
\hline Greece & 2007 & 2013 & 72 & 98 & 174.95 \\
Iceland & 2008 & 2013 & 36 & & 85.2 \\
Ireland & 2007 & 2012 & 6 & 16 & 120.24 \\
Italy & 2008 & 2013 & 111 & 122 & 128.54 \\
Portugal & 2008 & 2013 & 62 & & 129.66 \\
Ukraine & 2006 & 2011 & 14 & 39 & 36.88 \\
UK & 2008 & 2012 & 43 & 53 & 85.82 \\
USA & 2008 & 2013 & 55 & 67 & 104.78 \\
\hline
\end{tabular}


sufficient to carry out debt sustainability analysis on some mean value projected trajectory of macroeconomic, fiscal, and financial variables, and then analyze a few extreme scenarios. We need to capture the correlations of risk factors and integrate the debt financing decisions with the correlated scenarios to get distributions of final outcomes and a rigorous measure of extreme event risk. These distributions can be used to trade-off cost and risk, following well-established practices of portfolio management.

An important step in the direction we suggest was made recently by Guzman and Lombardi (2017), who develop an elaborate infinite-horizon model of the risk factors of an indebted economy and use it through simulations to answer questions Q1 and Q2. Their work does not optimize a debt financing strategy, however they do consider debt sustainability constraints including principles-based constraints that can be of a political or normative nature. Their work and ours (Consiglio and Zenios 2016) make complementary contributions. Optimization modeling applies naturally to their framework, and the economic models they develop can be the basis for scenario generation in our models.

\subsection{The scenario tree structure}

We adopt the discrete time-space, discrete state-space framework of multi-period stochastic programming that dates back to the early days of linear programming (Dantzig 1963; Kall and Wallace 1993). Decisions are made here-and-now based on all available information and anticipating future uncertain information that is represented in a scenario tree. As new information arrives we make recourse decisions that are adapted to the tree state. This setup captures important features of debt management:

1. Term structure of legacy debt with multiple debt issues of different maturities;

2. Clustering of maturities around specific dates with the associated roll-over risk;

3. Correlated risk factors for macroeconomic, fiscal, and financial variables.

In this setting, we can optimize risk metrics of debt stock at the risk horizon or of gross financing needs at intermediate time periods to avoid rollover risk. Thus, we can optimize debt stock, debt flow, or both jointly.

The key parameters follow some stochastic processes, possibly correlated. We consider in particular:

1. Stochastic GDP growth;

2. Stochastic fiscal variables: government revenues and expenditures, primary surplus/deficit;

3. Stochastic term structure of interest rates for financing a country's debt.

The discrete state-space, discrete time-space setup is represented by a scenario tree, such as the one illustrated in Fig. 2. A model is built on this tree up to some risk horizon $\left(T_{R i s k}\right)$ although debt may extend decades into the future $\left(T_{\text {Data }}\right)$. When providing some mathematical formalism later on we use $t$ to denote time and $n$ to denote states, but we do not give the formal definition of a tree nor do we give full 


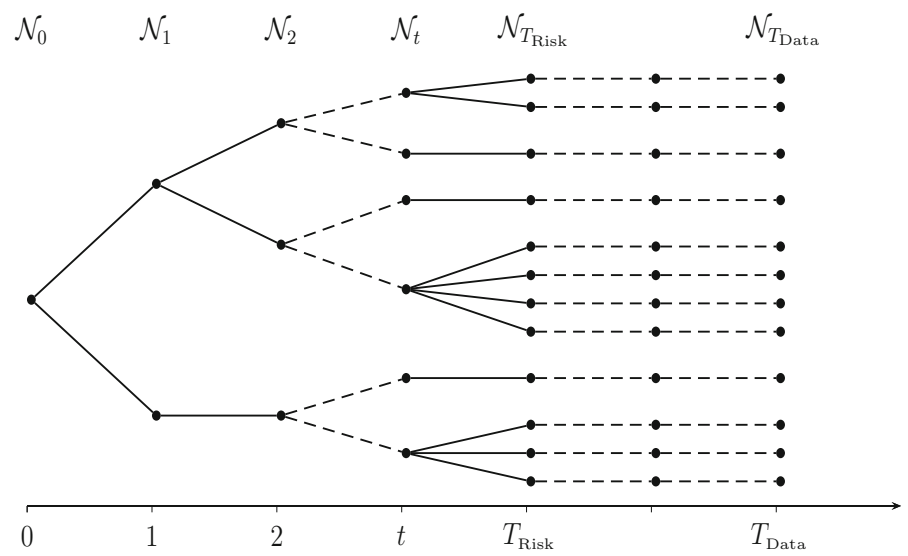

Fig. 2 A scenario tree

model specifications. Interested readers are referred to Zenios (2007, Chaps. 6, 9) for background. Probabilities are attached to all states of the tree and can be used to estimate the probability of each path, and $\pi^{n}$ denotes the probabilities of terminal states. For uniformly branching trees, the terminal states are equiprobable with probability equal to $1 /$ (number of terminal states). For non-symmetric trees, such as the one of Fig. 2, terminal probabilities are the joint probability of all states on a path. If the branching is not conditioned on the state, but is fully determined at the first time period, we recover the fan chart approach of IMF staff (Celasun et al. 2006). Tree calibration should match market - observed moments of the risk factors (including correlations) and be consistent across risk-neutral and objective probability measures (Consiglio et al. 2016). Alternatively, one could calibrate a tree based on economic equilibrium models such as the one of Guzman and Lombardi (2017).

At the core of sovereign debt management are the treasury decisions to issue debt of different types to cover gross financing needs. Gross financing needs are the legacy debt net any primary surplus net any one-off adjustments to debt stock from, for example, privatization proceeds. The type of debt denotes different maturity dates, different covenants, adjustable or fixed rate loans, or official sector loans under ESM or IMF terms. The treasury decisions define the debt financing strategy for the sovereign and are the variables of the models.

\subsection{Key parameters}

Going from debt sustainability to stochastic debt sustainability analysis requires, first, that the economic, fiscal, and financial parameters are state dependent. Debt can be in domestic or foreign currency, in which case FX risk is introduced, and debt parameters can be in nominal values (typically) or in real values, in which case inflation risk comes into play. The key parameters of the problem follow. 
$G D P$

Legacy debt,

Government primary

balance,

Stock flow adjustment of debt,

Interest rate on debt, denoted by $Y^{n}$, with growth rate $g^{n}$.

denoted by $L^{n}$. This is the country's payment obligations due to legacy debt as a two-dimensional matrix, with one dimension denoting debt payments across time and the other denoting debt instruments. Entries of this matrix are the payments due for principal at maturity, interest, and amortization. Legacy debt is expressed in terms of principal amortization and interest, respectively, as:

$$
L^{n}=L A^{n}+L I^{n} .
$$

Legacy debt and its components are identical at all states of a given time period when dealing with fixed-rate debt. For floating rate debt or GDP-linked bonds or sovereign contingent convertible bonds, legacy debt is state-dependent. denoted by $P B^{n}$, represents the government revenues minus government expenditures excluding debt servicing costs. For states with $P B^{n}>0$ the government is running a primary surplus and can pay down debt, whereas $P B^{n}<0$ denotes primary deficit that increases debt.

denoted by $S F^{n}$, consists, for example, of one-off proceeds from privatization or haircuts in case of debt restructuring. denoted by $r^{n}$, is the full term structure of interest rates.

\subsection{Variables}

The main variable of the model is the amount of debt to be issued at each state $n$ at each time period $t$. The types of instruments available for debt financing are indexed by $j$, and the terms of each instrument determine the amount and timing of payments that the borrowing country must make in the future. We introduce the following notation:

1. $x^{n}(j)$ denotes the amount of debt issued using instrument type $j$ at state $n$. Ratio to GDP is computed when estimating debt stock or flow risk metrics.

2. When issuing one unit of instrument $j$ the government assumes a future liability. $C F^{n}(j, m)$ denotes the amount due at state $n$, per unit $x^{m}(j)$ issued at state $m$ on the path that goes through $n$. This is a parameter that can be computed from the scenarios of the term structure of interest rates and the contractual terms of the instruments. However, if the interest rate or other terms of the issued debt depend on the amount issued this parameter becomes endogenous. We discuss this issue in Sect. 7.1.

3. $G F N^{n}$ denotes the gross financing needs of the country at $n$. These are determined by the legacy debt, the government primary balance, the one-off stock flow adjustments, and the debt servicing payments for debt issued at some previous state $m$ that are due at $n$. This variable is specified in Sect. 2.1.1. 
4. $M I^{n}$ denotes the amount of debt to be financed by issuing market securities. Part of this is exogenous and depends on the country's legacy debt and fiscal conditions, and part is endogenous and depends on debt financing decisions. This variable is specified in Sect. 2.1.1.

\section{Key equations}

We now define key relationships between model parameters and variables. We start with the accounting identities and then define risk measures for debt stock at the risk horizon and for debt flow at intermediate time periods.

In general, from empirical studies on debt sustainability, we want stock debt-toGDP ratio below 120\% and flow of gross financing needs-to-GDP less than 15-20\% (Gabriele et al. 2017). These two parameters are used to constrain the risk measures.

We drop the time index when iterating over all states on the tree, since each $n$ corresponds to some $t$. We explicitly use time index for the risk horizon $T_{\text {Risk }}$ that requires special treatment.

\subsection{The accounting identities}

Cash-flow conservation is modelled at each state $n$.

\subsubsection{Gross financing needs and market issuance}

The gross financing needs of the country at state $n$ are given by:

$$
G F N^{n}=\underbrace{L^{n}}_{\text {Legacy debt. }}-\underbrace{\left(P B^{n}+S F^{n}\right)}_{\begin{array}{c}
\text { Country scenarios, } \\
\text { consitent with } \\
\text { GDP projections. }
\end{array}}+\sum_{m} \sum_{j} x^{m}(j) C F^{n}(j, m) .
$$

Most of these needs are financed by issuing debt in the markets given by:

$$
M I^{n}=\underbrace{L^{n}-P B^{n}-S F^{n}}_{\text {Exogenous debt. }}+\underbrace{\sum_{m} \sum_{j} x^{m}(j) C F^{n}(j, m)}_{\text {Endogenous debt. }} .
$$

\subsubsection{New debt issues}

The sovereign issues different instruments to meet the gross financing needs. The total amount of debt to be issued at each $n$ is given by:

$$
\sum_{j} x^{n}(j)=M I^{n}
$$




\subsubsection{Debt stock}

The debt stock at each state of the economy consists of the debt at the predecessor state $p(n)$ plus new exogenous debt. To account for endogenous debt that was created at some predecessor state but matures at the current state to be financed through market issuance, we use the indicator function $\mathbb{1}^{n}(j, m)$ to denote whether instrument $j$ issued at some state $m$ matures at $n$. Debt stock is given by the recursive relation:

$$
D^{n}=D^{p(n)}+M I^{n}-\sum_{m} \sum_{j} x^{m}(j) 1^{n}(j, m)-L A^{n} .
$$

\subsection{Risk measure of debt stock}

The debt-to-GDP ratio $d$ at the end of the risk horizon is given by:

$$
d^{n}=\frac{D^{n}}{Y^{n}}, \text { for all states } n \text { in the set of states at } T_{R i s k} .
$$

This critical variable for debt sustainability analyses is stochastic, and we are interested not only in its mean but also in higher moments and, especially, in the extreme values. The "devil is in the tails" we argued elsewhere (Consiglio and Zenios 2015) for crisis countries, and a rigorous measure of the tail must be introduced and carefully examined.

The mean value of $d$ for the states at the risk horizon $T_{\text {Risk }}$ is given by:

$$
\mathbb{E}[d]=\sum_{n} \pi^{n} d^{n}
$$

A risk measure of the tail is the expected value of $d$, conditioned on $d$ being higher than its quantile at confidence level $\alpha$. We call this risk measure Conditional Debtat-Risk (CDeaR). That is, CDeaR $=\mathbb{E}\left[d \mid d \geq d^{*}\right]$, where $d^{*}$ is the left $\alpha$-percentile of the debt-to-GDP ratio $d$, i.e., the lowest possible value $d^{*}$ such that the probability of debt-to-GDP ratio less than or equal to $d^{*}$ is greater or equal to $100 \alpha$.

This risk measure of the tail is not ad hoc. It applies the well known Conditional Value-at-Risk $(\mathrm{CVaR})$ to the random variable $d$, i.e., $\mathrm{CDeaR} \doteq \mathrm{CVaR}[d] . d^{*}$ is the Value-at-Risk ( $\mathrm{VaR})$ at the $\alpha$ probability level, which is an industry standard for bank risk management. The definitions are illustrated in Fig. 3. CVaR, and closely related risk measures, are widely used in finance and insurance where they have been acclaimed due to their coherence, satisfying a set of axioms that characterize admissible portfolios. However they are less known to the economists who typically deal with sovereign debt analysis. The seminal contribution is Artzner et al. (1999), and Rockafellar and Uryasev (2002) showed that CVaR can be optimized using linear programming. From their work we can compute CDeaR in the context of portfolio optimization using the following equation and inequalities for $n$ in the set of states at $T_{\text {Risk }}$ : 


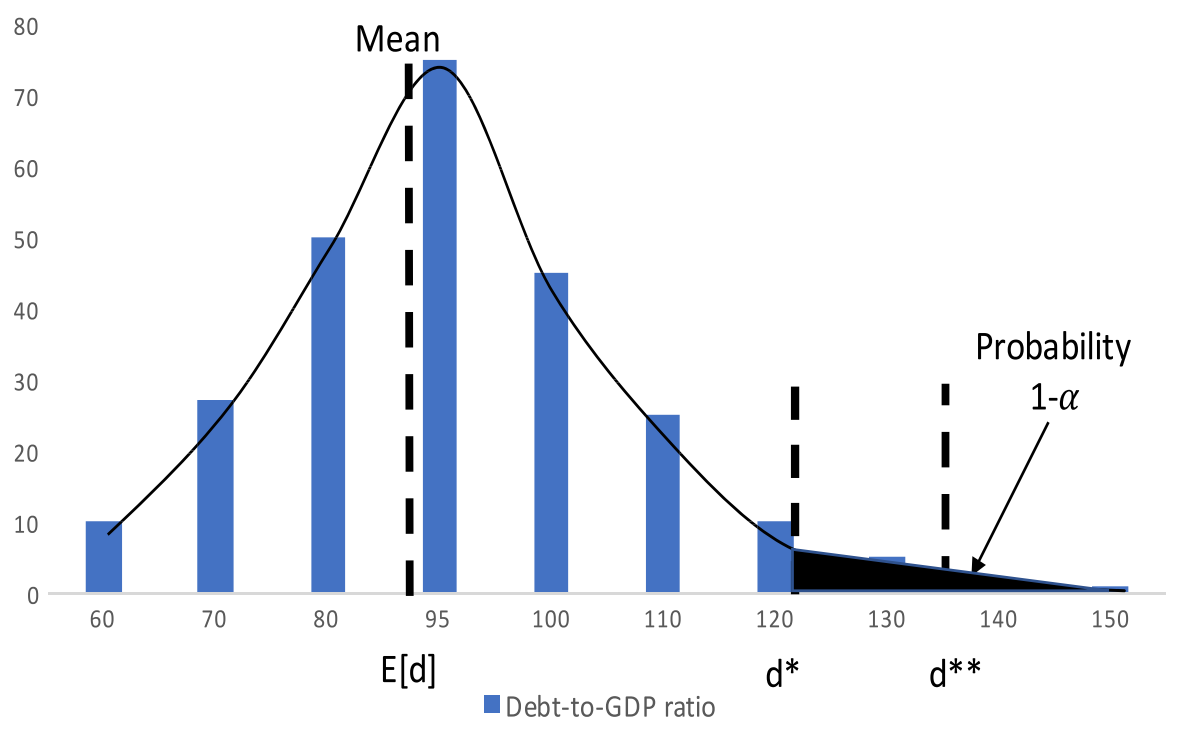

Fig. 3 Distribution of debt-to-GDP ratio and illustration of $d^{*}=\operatorname{VaR}[d]$ and $d^{* *}=\operatorname{CVaR}[d]$

$$
\begin{gathered}
d^{* *}=d^{*}+\frac{1}{1-\alpha} \sum_{n} \pi^{n} y^{n} \\
y^{n} \geq d^{n}-d^{*} \\
y^{n} \geq 0 .
\end{gathered}
$$

$y^{n}$ is a dummy variable denoting the non-negative values of debt in excess of $d^{*}$. An optimization model can be used to bound CDeaR by a threshold with high probability (e.g., $\alpha=0.95$ ).

\section{Stock optimization model}

The distribution of the random variable $d$ depends on debt financing decisions, the schedule of legacy debt, and economic, fiscal, and financial random variables. A stock optimization model minimizes the expected value of debt-to-GDP ratio while restricting the risk measure CDeaR below a threshold. The risk measure is expressed not in debt values but in debt-to-GDP ratio. However, we do not need to express all variables as ratios to GDP. Instead we use absolute values and convert to ratios when needed. For the debt stock model we compute debt-to-GDP ratio for the final debt stock and impose CDeaR constraints on this ratio.

An optimization model minimizes the expected cost of debt stock as a ratio to GDP, with a parametric limit $\delta$ on the risk measure CDeaR at the risk horizon. Varying $\delta$ we trace an efficient frontier of expected cost versus CDeaR. Solutions on the frontier represent different debt financing policies and we can identify those that are sustainable at the $\alpha$ confidence level. 


\section{Flow optimization model}

An alternative model is to optimize the flow of gross financing needs to limit rollover risk. To this end we compute gross financing needs-to-GDP ratios for intermediate debt flows:

$$
g f n^{n}=G F N^{n} / Y^{n}, \text { for all states } n \text { and all time periods } t .
$$

For each time period $t$ the gross financing needs-to-GDP ratio is a discrete stochastic variable taking values on the states at $t$. Figure 4 illustrates on our scenario tree. To limit debt rollover risk this ratio is bounded by a threshold $\omega$. But what does it exactly mean to bound gross financing needs? We consider all time periods $t$ and

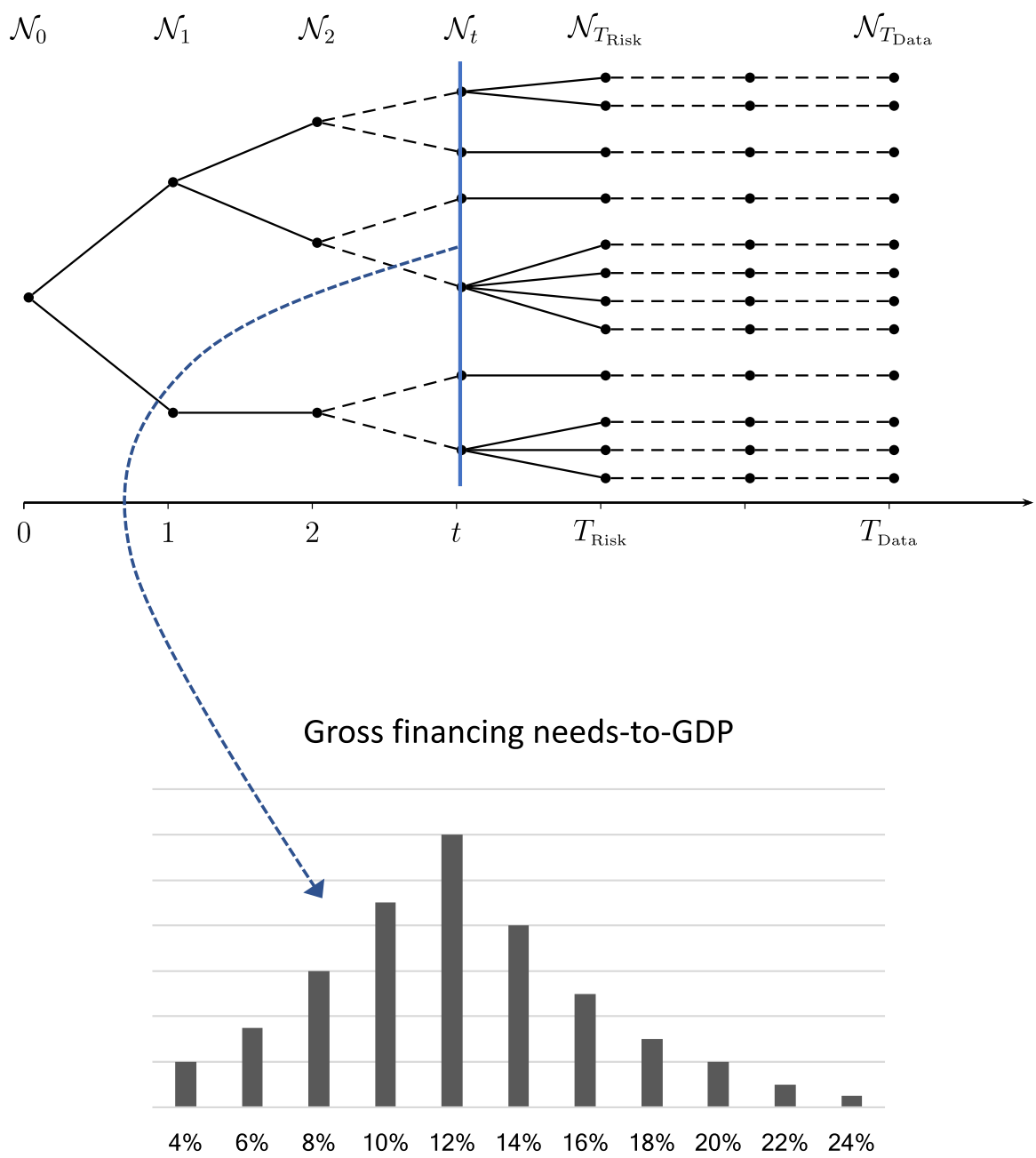

Fig. 4 Distribution of gross financing needs-to-GDP ratio at intermediate time period $t$ 
the states $n$ corresponding to each period, and look at different ways of imposing bounds.

\section{Conservative}

Constrain the ratio for all states of the economy at each time period:

$$
g f n^{n} \leq \omega, \text { for all } n .
$$

\section{Risk neutral}

Constrain the expected value of the ratio at each time period:

$$
\mathbb{E}\left[g f n^{n} \mid \text { for all states } n \text { corresponding to } t\right] \leq \omega .
$$

\section{Risk adjusted probabilistic constrained}

Constrain the Conditional Flow of Debt Financing-at-Risk (CFDeaR) at confidence level $\alpha$. This is consistent with constraining CDeaR on debt stock at the risk horizon. For each time period we compute CFDeaR and limit it by $\omega$. The use of CVaR constraints for risk shaping was discussed in Rockafellar and Uryasev (2002) and there is a precedent in multi-period models for credit risk portfolios (Jobst et al. 2006).

A simpler formulation is to minimize CFDeaR over all time periods and over all scenarios jointly. While this formulation does not guarantee that CFDeaR will be below the threshold at every time period, it minimizes the aggregate risk of financing needs.

The CFDeaR at $t$, denoted by $g f n_{t}^{* *}$, is modeled using the following system of equation and inequalities in the context of a portfolio optimization model:

$$
\begin{gathered}
g f n_{t}^{* *}=g f n_{t}^{*}+\frac{1}{1-\alpha} \sum_{n} \pi^{n} z^{n} \\
z^{n} \geq g f n^{n}-g f n_{t}^{*} \\
z^{n} \geq 0
\end{gathered}
$$

where $n$ is the set of states corresponding to $t$ and $g f n_{t}^{*}$ is the VaR of gross financing needs-to-GDP ratio (flow debt-at-risk) at $t$. The simpler formulation considers $g f n^{n}$ as a random variable over all states $n$ at all times and computes CFDeaR by:

$$
\begin{gathered}
g f n^{* *}=g f n^{*}+\frac{1}{1-\alpha} \sum_{n} \pi^{n} z^{n} \\
z^{n} \geq g f n^{n}-g f n^{*}, \\
z^{n} \geq 0 .
\end{gathered}
$$

$g f n^{*}$ is the VaR of aggregate gross financing needs. This system of equations and inequalities can be used in an optimization model to minimize the aggregate risk of gross financing needs or to vary $\omega$ and trace an efficient frontier of expected cost versus CFDeaR. 


\subsection{Smoothing of gross financing needs}

Bounding the tail is not the end of the story. A sovereign's gross financing needs should not fluctuate with time according to the arguments for taxation smoothing put forth by Barro (1979). This requirement can be implemented by bounding the changes of gross financing needs. Dummy variables $w^{+}(n)$ and $w^{-}(n)$ measure, respectively, increases and decreases in gross financing needs and we formulate:

$$
\begin{aligned}
& w^{+}(n) \geq g f n^{n}-g f n^{p(n)} \\
& w^{-}(n) \geq g f n^{p(n)}-g f n^{n},
\end{aligned}
$$

where $p(n)$ is the predecessor state of $n$. The following inter-temporal smoothing constraint is now added to the flow model:

$$
\frac{1}{\mid \text { Number of states } \mid} \sum_{n} w^{+}(n)+w^{-}(n) \leq \lambda .
$$

$\lambda$ can be set to a large value, ignoring smoothing, or adjusted to the smallest value that permits a feasible solution, thus achieving the best possible smoothing.

\subsection{Flow optimization with fixed-mix strategies}

A key feature of our modeling so far has been that the decision variable $x^{n}(j)$ is adapted to the state. This is a key feature of stochastic programming and the tree structure precludes decisions from being adapted to states that have not yet been observed. The stochastic programming model prescribes a policy that is adapted as new information becomes available, without clairvoyance. A decision maker will implement a decision, wait to observe the state at the next time period, implement the decision prescribed for that state, and wait again. He or she is following a dynamic portfolio strategy that has been optimized by the stochastic program.

A simpler approach is to search for portfolio weights that will be implemented at all times and for all states. This would be a fixed-mix portfolio strategy and is much closer to the practice of public debt management officers. A simple strategy gives a clear signal to investors about the country's intentions. In linear scenario fan structures, as opposed to tree structures, all information is revealed after the first time period, and a fixed-mix optimization model strategy is more appropriate since the stochastic program would adapt to information in the linear structure that is assumed to be known after the first time period, but in practice it will not be so.

The estimation of a fixed-mix strategy can also be set up as an optimization model. This model is more constrained than the stochastic program and will generate more expensive solutions. Furthermore, the model is non-linearly constrained and more difficult to solve. For large scale applications this may pose algorithmic challenges. We consider two alternative models using fixed-mix strategies. The simplest assumes a fixed-mix for all states and times, while a more advanced version adapts the mix with time but not with states. 


\subsubsection{Constant fixed-mix strategy}

We introduce a decision variable vector $w(j)$ of proportional weights in asset $j$, which is independent of states or time periods. The asset allocation at state $n$ is determined by adding the following constraints to the flow model:

$$
\begin{gathered}
x^{n}(j)=w(j) M I^{n}, \\
\sum_{j} w(j)=1 .
\end{gathered}
$$

Equation (23) introduces non-linearities since $M I^{n}$ is an equation in $x$.

\subsubsection{Adapted fixed-mix strategy}

Now introduce a decision variable vector $w(t, j)$ of proportional weights in the $j$ th asset, which is independent of the states but adapts with time, and constraints are introduced for each time period $t$ :

$$
\begin{gathered}
x^{n}(j)=w(t, j) M I^{n}, \\
\sum_{j=i}^{J} w(t, j)=1 .
\end{gathered}
$$

Equation (25) is also non-linear and there is one such equation for each time period.

\section{Joint debt and flow optimization models}

We now synthesize joint models of debt stock and flow. The discussion is simplified by defining generic functions of debt stock and gross financing needs in terms of issued debt and interest rates:

$$
\begin{gathered}
D^{n}=F\left(x^{n}, r^{n}\right) \\
G F N^{n}=G\left(x^{n}, r^{n}\right) .
\end{gathered}
$$

For sustainability analysis we are interested in the ratio of debt stock and debt flow to GDP and the definitions $d^{n}=D^{n} / Y^{n}$ and $g f n^{n}=G F N^{n} / Y^{n}$ apply.

Debt stock that increases with time is unsustainable and so is debt with gross financing needs exceeding a threshold, empirically set at 15-20\% of GDP at each time period. Since both quantities are stochastic we trade off their expected value with a measure of risk, using the Conditional Value-at-Risk CVaR $[d]$ and $\mathrm{CVaR}[g f n]$, for stock and flow respectively.

There are two ways to control simultaneously debt stock and gross financing needs. One approach is to optimize gross financing needs by trading off expected value and risk of gross financing needs, with sustainability constraints on stock. An alternative is to optimize debt stock by trading off expected value and risk of stock, with sustainability constraints on gross financing needs. 


\subsection{Optimizing gross financing needs}

The first joint model minimizes the expected cost of gross financing needs while bounding the risk measure $\mathrm{CVaR}[g f n]$ by a parameter $\omega$. To ensure debt sustainability for highly indebted countries, we constrain debt-to-GDP ratio to be non-increasing with time. This follows, for example, from the Growth and Stability Pact of the EU. A canonical formulation is given by:

$$
\begin{aligned}
& \text { Minimize } \mathbb{E}[g f n] \\
& \text { s.t. } \\
& \operatorname{CVaR}[g f n] \leq \omega \\
& \frac{\partial d^{n}}{\partial t} \leq 0, \text { for all } n .
\end{aligned}
$$

The last constraint ensures that debt stock is non-increasing with time. A milder sustainability condition is that increasing debt should reach a steady state below some threshold. This model is a large-scale linear program parametrized with $\omega$, or a nonlinear program if a fixed-mix financing strategy is desirable.

\subsection{Optimizing debt stock}

The second joint model minimizes the expected debt-to-GDP ratio at the end of the risk horizon while bounding the risk measure $\mathrm{CVaR}[d]$ by a parameter $\delta$. To ensure debt sustainability we bound gross financing needs up to $20 \%$ of GDP. The canonical formulation is given by:

$$
\begin{gathered}
\text { Minimize } \mathbb{E}[d] \\
\text { s.t. } \\
\operatorname{CVaR}[d] \leq \delta \\
\operatorname{CVaR}[g f n] \leq 20 \% .
\end{gathered}
$$

This is a large-scale linear program parametrized with $\delta$, or a nonlinear program when optimizing a fixed-mix financing strategy.

\section{The challenge of infeasibility}

Model infeasibility reveals unsustainable debt. Either the debt-to-GDP ratio does not satisfy the non-increasing condition (31) or gross financing needs fail to satisfy (34). Declaring a model infeasible, however, is a very crude answer to a complex question. First, debt-to-GDP ratio limits may be violated for a very small set of extreme scenarios. Is that really an unsustainable situation? No, if the probability of violating the sustainability constraints is less than the tolerance (i.e., 5\%). It is also 
useful to know for how many and for which scenarios sustainability is violated. Furthermore, when the constraints are violated, question Q2 is raised on how to restore sustainability through debt restructuring.

We need a model that gives feasible solutions which can be used to assess scenarios that violate debt sustainability. Optimization theory allows us to introduce slack variables on the sustainability constraints (31) or (34), with a big-M penalty cost. The models are then always feasible and we can compute, ex post, the percentage of scenarios that violate the sustainability constraints by counting the non-zero slack variables. Thus we answer question Q1 "Is debt sustainable with high probability?". The solution also reveals if sustainability is violated due to excessive gross financing needs at some periods or long-run debt-to-GDP growth.

If slack variables are non-zero at optimality, debt is unsustainable and Q2 is raised: "What debt restructuring schedule will restore sustainability?". This can also be addressed with optimization modeling. However, there is an ongoing debate on the requirements of a debt restructuring process (Guzman and Stiglitz 2015), and an optimization model is likely to be evasive for some time. Some possibilities are to minimize the net amount written down by the creditors, to reschedule legacy debt obligations, or provide interest rate concessions. An optimization model calculates debt restructuring that is neither too much nor too little. Identifying the appropriate level of debt restructuring is a contested point during negotiations when debtors want more and creditors accept less, and an optimization model provides a benchmark.

Note that the value of the slack variables, or debt restructuring variables in case of non-zero slack, depends on $x^{n}(j)$. Hence, the model answers Q3 and identifies a financing strategy for restructured debt.

\section{Data endogeneity}

An economy will respond to policy actions, and when modeling, especially, a country in crisis we need to address the main sources of data endogeneity. In the context of debt sustainability analysis we know that a country's financing rates will depend on the country's debt, and the ability to generate primary surplus depends on debt overhang. These effects deserve modeling as they may create vicious or virtuous circles. If a country builds excessive debt, then it is charged high rates, which makes it necessary to raise even more debt, creating a vicious circle. On the other hand, if debt is reduced and interest rates drop, the country can pay down its debt and benefit from further interest rate reductions in a virtuous circle.

\subsection{Effect of debt on interest rates}

The sovereign's borrowing rates depend on the debt-to-GDP ratio and we need to model the effect of debt-to-GDP ratio-which depends on model decisions-on debt refinancing rates-which up to now were given exogenously. A relationship between a country's interest rates and indebtedness is given by 


$$
r=r_{f}+\rho,
$$

where $r_{f}$ is the risk-free rate and $\rho$ is the country risk premium. For instance, following Blanchard et al. (2016), we can allow the risk premium to change by $2 \mathrm{bp}$ for every percentage point deviation of the debt-to-GDP ratio from a baseline and by 3 bp per percentage point when debt ratio exceeds $140 \%$. For eurozone countries we can consider an increase of the risk premium by $3 \mathrm{bp}$ for each percentage point upside deviation from the Growth and Stability Pact ratio of $60 \%$. Alternatively, and this is a topic of current debate by economists, we could consider gross financing needs as the main factor driving the premium and calibrate appropriately a regression model. A sigmoid function captures the nonlinear effects of debt or gross financing needs on the financing rates, accounting for upper and lower bounds.

\subsection{Effect of debt on primary balance}

The ability of a country to generate primary surplus also depends on debt overhang through the mechanism of "fiscal fatigue". Hence, another type of endogeneity is introduced whereby the primary balance $P B^{n}$ depends on the debt-to-GDP ratio and on debt financing decisions. This aspect of the model is critical in generating solutions that are not only sustainable but also socially acceptable. Consider a strategy whereby the citizens of a country work for one year full time without any compensation. They will repay debt equal to the country's GDP and maybe restore debt sustainability but the country will be devastated. Principles-based constraints can be introduced to guarantee, for example, a minimum level of consumption for the citizens.

We hasten to add that modeling some data endogenously is not a substitute for accurate, correct and consistent scenarios in the first place (Zenios 2007, Chap. 9). For instance, in the analysis of Consiglio and Zenios (2016) for the case of Greece we found that if one accepts the IMF projections of primary surplus and growth, then Greek debt was sustainable. However, there is no historical precedence of a country achieving the targets set for Greece.

\section{Strategic or operational models and post-optimality analysis}

The reader must be getting the impression that sovereign debt sustainability is a rich problem with many possibilities for optimization modeling. This is indeed our view. We add now another dimension to the richness of the models, which also serves as a warning about pitfalls.

Question Q1 on whether debt is sustainable with high probability is a strategic question. It is typically answered by considering a very long horizon (30-40 years, depending on the maximum maturity of a country's legacy debt, $T_{\text {Data }}$ ). There is an underlying financing strategy but this extends over a very long horizon and the sovereign will be revising the strategy, so we are interested more in the optimal objective value than the optimal solution vector $x^{*}$. The same is true for question Q2 on the amount of debt that needs to be written down. The models provide an 
aggregate answer that is valid over a long horizon. However, deciding a debt financing strategy in Q3 requires an operational model. The optimal solution vector becomes relevant, but we can not expect to have an optimal solution over a very long horizon. Operational models typically extend to 5 years, or maybe up to 10 if we are ambitious modelers.

International institutions that consider an assistance program for the sovereign are facing firstmost a strategic decision. The country's public debt management office deals with the operational decisions, and in this case other practical issues come up such as the need for the country to offer debt of varying maturities, to smooth out any clustering of debt maturities from legacy debt, to trade off the low cost of short-term financing with the increased rollover risk, and so on. These issues can be addressed through post-optimality analysis, whereby the public debt management office can use model solutions to design a strategy that satisfies short run practical (including political and policy) requirements.

In going from a strategic to an operational model end effects must be mitigated. We are using a finite horizon model to solve an infinite horizon problem, and the question is raised on the effects of truncating the risk horizon. Does it affect the solution only as we approach the (truncated) horizon, in which case the truncation error can be safely ignored? Or does it affect the decisions of early stages, in which case a mitigation strategy must be devised? The pioneering work of Grinold (1983) and robust optimization of Mulvey et al. (1995) provide possible approaches for mitigating end effects.

One important issue that can not be overlooked, as it does not fit under the realm of truncation error, is that debt maturing past the risk horizon is outstanding debt and the risk measure must be properly adjusted. This can be done by including the nominal value of total outstanding debt in the calculation of debt-to-GDP ratio at terminal states. Alternatively, and more accurately, we could use a pricing model to discount debt payments from the maturity of the longest debt $T_{\text {Data }}$ to the risk horizon $T_{R i s k}$. The risk measure provides a signal of sustainability if it lower than an acceptable threshold with high probability. Without the adjustment to the risk measure the model emulates the myopic politician who plans until the end of his or her term and leaves the successor in a deep hole.

\section{Some comments on computations}

The stochastic programming model without data endogeneity is a linear program, and large-scale problems with hundreds of thousands of variables and tens of thousands of constraints can be solved using off-the-shelf software. The adaptive fixed-mix problem is a non-linearly constrained problem with a special non-linear constraint, cf. Eqs. (23) and (25). Small and medium size models can also be solved with relative ease, although it is computationally more expensive than the stochastic program and very large scale problems become challenging. Data endogeneity is another source of non-linearity. The resulting model can be poorly scaled if interest rates change abruptly when a sovereign's debt deviates from some acceptable level, or when excessive debt overhang makes it very difficult to create primary surplus. 
High level modeling languages are key to building models that can be easily understood by users. They also integrate state-of-the-art optimization algorithms, making it easy to move from linear to nonlinear models. In our own work we found that linear stochastic programs on a tree with 1024 scenarios can be solved routinely. For the highly nonlinear models with endogeneity, trees of 64 scenarios are easily solved but beyond that the computational demands are nontrivial. In general, model development and testing can take place on 64-scenario trees and production runs done with extra effort on 1024-scenario trees. Table 2 summarizes some illustrative data on the computational demands. The problem sizes in the table are obtained from the modeling language and do not correspond to the most compact formulations, as our implementation gives more emphasis on readability than compactness.

\section{Caveat: the Kingdom of Atlantis}

Based on some of our own work we model Atlantis, a fictitious Kingdom sinking under excessive debt. Based on the model of Sect. 5.1 we analyze four decades at the beginning of the 26th century using (1) stochastic programming, (2) adaptive fixed-mix, and (3) the Treasury's benchmark constant fixed-mix with debt issued evenly in $1 / 3$ short, medium and long maturities, respectively. The expected gross financing needs are as follows:

\section{Constant fixed-mix (benchmark) Adaptive fixed-mix Stochastic program}

\section{$13.11 \%$ of GDP $8.82 \%$ of GDP $8.32 \%$ of GDP}

Stochastic programming has the lowest expected cost and the Treasury's benchmark is a distant third. Looking at the debt-to-GDP ratio from the stochastic program (Fig. 5) the King of Atlantis sees good news. The probability of debt breaching a sustainability threshold is less than 5\% and it takes 39 years to reach the critical value. Atlantis public finances appear sound for the foreseeable future.

Table 2 Problem size and solution times for different models

\begin{tabular}{|c|c|c|c|c|c|}
\hline \multirow[t]{2}{*}{ Model (no. of scenarios) } & \multirow[t]{2}{*}{ Non-linearities } & \multicolumn{2}{|c|}{ Problem size } & \multirow{2}{*}{$\begin{array}{l}\text { Model setup } \\
\text { min:sec }\end{array}$} & \multirow{2}{*}{$\begin{array}{l}\text { Solution time } \\
\text { hrs:min:sec }\end{array}$} \\
\hline & & Variables & Constraints & & \\
\hline Stochastic program (64) & No & 26,451 & 37,030 & 00:01 & 00:00:05 \\
\hline Stochastic program (1024) & No & 402,771 & 563,878 & $00: 20$ & $02: 25: 12$ \\
\hline Adaptive fixed-mix (64) & Yes & 24,068 & 24,065 & 00:01 & 00:00:35 \\
\hline Adaptive fixed-mix (1024) & Yes & 362,756 & 362,753 & $00: 18$ & $03: 17: 45$ \\
\hline Adaptive fixed-mix (64) & Endogeneity & 29,272 & 29,183 & 00:05 & 00:01:16 \\
\hline Adaptive fixed-mix (1024) & Endogeneity & 443,224 & 443,135 & $18: 59$ & 05:52:07 \\
\hline
\end{tabular}




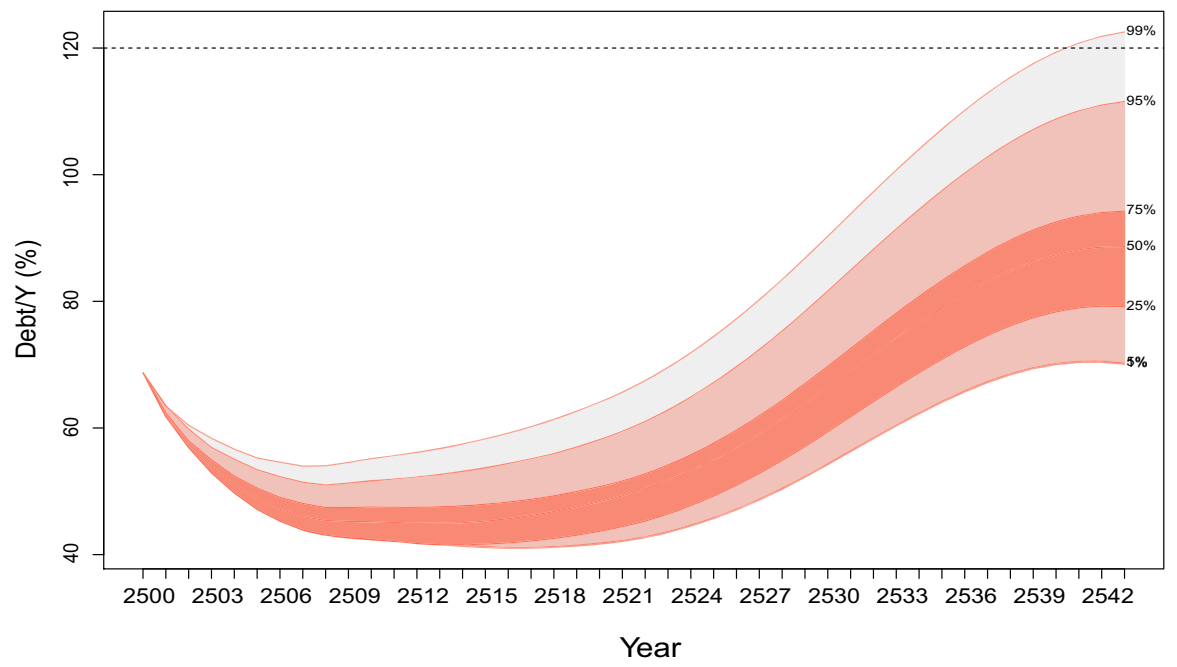

Fig. 5 Debt-to-GDP ratio for Atlantis and debt stock sustainability threshold (dashed line)

A more astute, and younger, Princess worries about the long run prospects and takes a careful look into the gross financing needs (Fig. 6). She makes two disconcerting observations. First, with probability $5 \%$ the debt ratio starts increasing by the seventh year (Fig. 5). On the average, debt burden starts growing around 2515. Second, the gross financing needs fan charts show that the cheaper financing strategy using stochastic programming is very volatile (Fig. 6). The expected savings of about .5\% GDP over the adaptive fixed-mix strategy are not worth the more elaborate model. However, with the current Treasury practices there is about $20 \%$ chance that gross financing needs will be unsustainable by the time she takes over the reigns in thirty years. The adaptive fixed-mix strategy generates average savings of $4.3 \%$ of GDP and is sustainable at the $100 \%$ confidence level over the horizon. These results show that Atlantis is not as safe as the King had concluded, but it has a few years to put its public finances in order. Difficulties come from inability to secure financing in the medium run and from long run excessive debt growth. The Princess quotes Arthur Geoffrion that "the purpose of mathematical programming is insight, not numbers", and suggests that the Treasurer gets to work with the optimization experts to find ways to restore sustainability of public finances over the next fifteen years.

This story may be fictitious but it is not unrealistic. It describes the predicament facing countries in a debt crisis. Optimization experts who delve into the sovereign debt problem face many complex legal, policy, and political issues that do not fit neatly in a system of inequalities and an objective function. Economic theories that generate data are more often than not controversial, as we have witnessed in the austerity debate in Europe. A clean black-box model is unlikely to emerge, but very powerful tools are possible to support policymaking.

How do we turn model insights into policy? The word "optimization modeling" instead of "optimization models" was purposefully used in the title. Musician, 

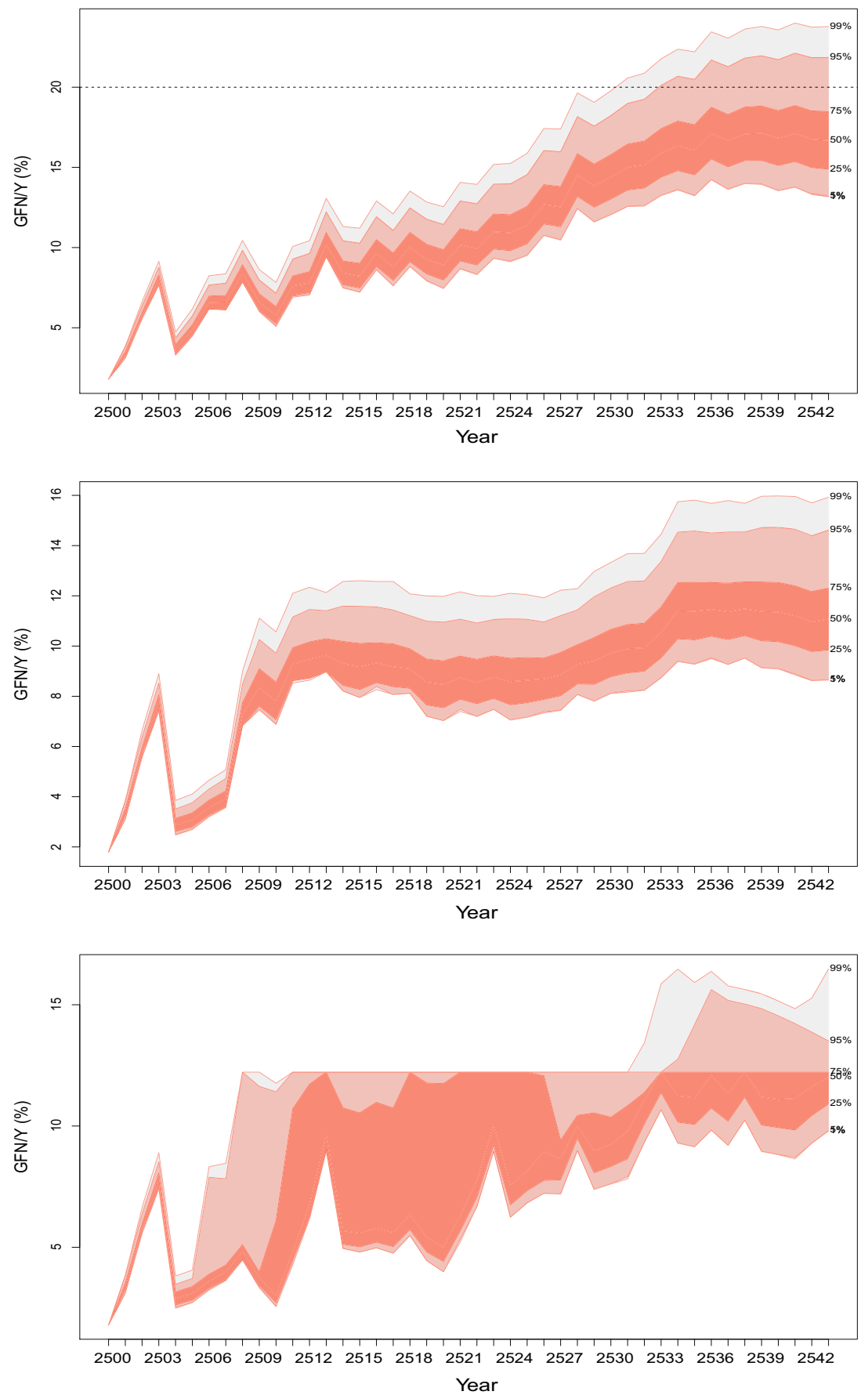

Fig. 6 Gross financing needs as a ratio to GDP. [Benchmark policy (top), adaptive fixed-mix (middle), stochastic program (bottom), debt flow sustainability threshold (dashed line)] 
educator and author Christopher Small in his classic book Musicking emphasizes that music is a process (verb) and not an object (noun). Same with models! The optimization modeler relates to the rest of the sovereign debt world which includes economists, mathematicians, policymakers and managers of international organizations, lawyers, bankers, and investors. It is only if this diverse world interprets the signal of the model that optimization modeling will be a value-adding process. For the model to emit a signal that can be decoded, the modeler must first make sense out of an apparent cacophony of demands during the modeling process. His or her job is to figure out what a model can and can not do, and educate the end users to understand the model signals.

There are three hurdles on the road to successful modeling: First, separate what the user wants from what the user needs. There are multiple users whose wants typically diverge but their needs are more convergent. Second, formulate and solve the optimization model and present the results in a digestible form. And, finally, work with the user to translate the model signal into policy. Of the three hurdles, model formulation, which has been the focus of this article, is perhaps the easiest.

\section{Conclusion}

Managing sovereign debt, especially for crisis countries, is an important societal problem. Recent experiences show that debt sustainability analysis must be augmented to account for the stochastic correlated risk factors that affect a country's debt situation. A risk measure then captures extreme events. The problem has been studied extensively by public- and macro-economists, but there is a dearth of normative models for both strategic and operational planning. Stochastic debt sustainability analysis lends itself naturally to optimization modeling using multiperiod stochastic programs. We have discussed several promising avenues for model development and illustrated using a fictitious, but not unrealistic, example. Most of our discussion was in terms of economic criteria for debt sustainability and optimization, but the framework lends itself also to principles-based constraints of a political or normative nature.

Acknowledgements The authors benefited from the comments of three anonymous referees and discussions with Marialena Athanassopoulou, Aitor Erce, Angel Gavilan, Anna Gelpern, Martin Guzman, Alex Meeraus, Enrique Mendoza, Edmund Moshammer, Joseph Stiglitz, Bill Ziemba, and seminar participants at the Finance Departments of the Wharton School and Rensselaer Polytechnic Institute, CIGI at Columbia University, Stevens Institute of Technology, Bank of England and European Stability Mechanism. Stavros Zenios is holder of a Marie Sklodowska-Curie fellowship funded from the European Union Horizon 2020 research and innovation programme under Grant Agreement No. 655092.

\section{References}

Alesina A, Prati A, Tabelini G (1990) Public confidence and debt management: a model and a case study of Italy. In: Dornbusch R, Draghi M (eds) Public debt management: theory and history. Cambridge University Press, Cambridge

Artzner P, Delbaen F, Eber J, Heath D (1999) Coherent measures of risk. Math Financ 9(3):203-228

Barro RJ (1979) On the determination of the public debt. J Polit Econ 87(5):940-971 
Beers DT, Nadeau J-S (2015) Database of sovereign defaults, 2015. Technical Report No. 101, Bank of Canada, Canada

Blanchard O, Mauro P, Acalin J (2016) The case for growth-indexed bonds in advanced economies today. Policy Brief PB16-2, Peterson Institute for International Economics, Washington, DC

Bohn H (1995) The sustainability of budget deficits in a stochastic economy. J Money Credit Bank 27:257-271

Buchheit LC, Gelpern A, Gulati M, Panizza U, di Mauro BW, Zettelmeyer J (2013) Revisiting sovereign bankruptcy. Technical report, Committee on International Economic Policy and Reform, Brookings, Washington, DC

Calvo GA (1988) Servicing the public debt: the role of expectations. Am Econ Rev 78(4):647-661

Celasun O, Debran X, Ostry JD (2006) Primary surplus behavior and risks to fiscal sustainability in emerging market countries: a "fan-chart" approach. Working Paper 06/67, International Monetary Fund, Washington, DC

Consiglio A, Zenios SA (2015) Greek debt sustainability: the devil is in the tails. VOX, CEPR's Policy Portal. http://www.voxeu.org/article/greek-debt-sustainability-devil-tails

Consiglio A, Zenios SA (2016) Risk management optimization for sovereign debt restructuring. J Glob Dev 6(2):181-214

Consiglio A, Carollo A, Zenios SA (2016) A parsimonious model for generating arbitrage-free scenario trees. Quant Financ 16(2):201-212

Dantzig G (1963) Linear programmng and extensions. Princeton University Press, Princeton

Dornbusch R, Draghi M (eds) (1990) Public debt management: theory and history. Cambridge University Press, Cambridge

Gabriele C, Athanasopoulou M, Erce A, Rojas J (2017) Debt stocks meets gross financing needs: A flow perspective into sustainability. Working Paper Series No. 24, European Stability Mechanism, Luxembourg, 2017

Grinold RC (1983) Model building techniques for the correction of end effects in multistage convex programs. Oper Res 31(3):407-431

Guzman M, Heymann D (2015) The IMF debt sustainability analysis. J Glob Dev 6(2):387-404

Guzman M, Lombardi D (2017) Assessing the appropriate size of relief in sovereign debt restructuring. Technical report, Centre for International Governance Innovation, Columbia University, New York

Guzman M, Stiglitz JE (2015) Creating a framework for sovereign debt restructuring that works, volume Too little, too late: the quest to resolve sovereign debt crises, chapter 1. Columbia University Press, New York

Guzman M, Stiglitz JE (2016) A soft law mechanism for sovereign debt restructuring. Based on the UN principles. International policy analysis. Friedrich-Ebert-Stiftung, New York

Jobst N, Mitra G, Zenios SA (2006) Integrating market and credit risk: a simulation and optimization perspective. J Bank Financ 30:717-742

Kall P, Wallace SW (1993) Stochastic programming. Wiley, Chichester

Krugman P (1988) Financing vs. forgiving a debt overhang. J Dev Econ 29:253-268

Li Y (2016) The long march towards an international legal framework for sovereign debt restructuring. J Glob Dev 6(2):329-341

Maurer N, Musacchio A (2006) The barber of Buenos Aires: Argentina's debt renegotiation. Case Study 9-706-034. Harvard Businss School, Cambridge

Minsky H (1986) Stabilizing an unstable economy. (Available by McGraw Hill, NY, 2008). Yale University Press, New Haven

Mulvey JM, Vanderbei RJ, Zenios SA (1995) Robust optimization of large-scale systems. Oper Res 43(2):264-281

Neck R, Sturm J-E (eds) (2008) Sustainability of public debt. MIT Press, Cambridge

Reinhart CM, Reinhart V, Rogoff K (2015) Dealing with debt. J Int Econ 96(Supplement 1):S43-S55

Rockafellar R, Uryasev S (2002) Conditional value-at-risk for general loss distributions. J Bank Financ 26:1443-1471

Sturzenegger F, Zettelmeyer J (2006) Debt defaults and lessons from a decade of crises. MIT Press, Cambridge Wright MLJ (2012) Sovereign debt restructuring: problems and prospects. Harv Bus Law Rev 2:152-198 Zenios SA (2007) Practical financial optimization. Decision making for financial engineers. Blackwell/ Wiley, Malden 